\title{
Community pharmacists' knowledge, attitudes and practices towards herbal remedies in Riyadh, Saudi Arabia
}

K.M. Alkharfy

$$
\begin{aligned}
& \text { معارف ومواقف وممارسات الصيادلة المجتمعيين تجاه العلاجات العشبية في مدينة الرياض بالسعودية } \\
& \text { خالد بن محمد الخرفي }
\end{aligned}
$$

الخلاصة: هناك زيادة في استهالك المنتجات العشبية التكميلية أو البديلة في كثير من أنحاء العالم. وقد اختيرت عينة مقطعية عَرْضية مؤلّفة من 115

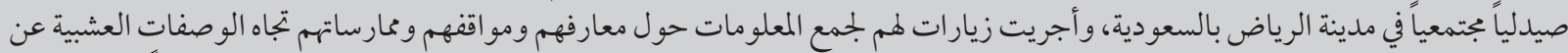

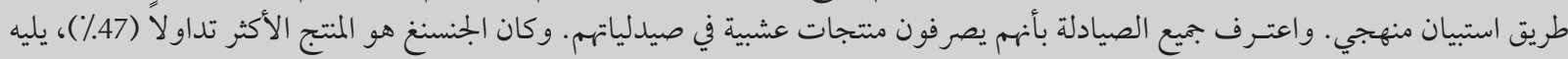

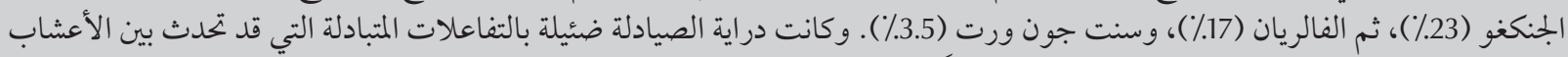

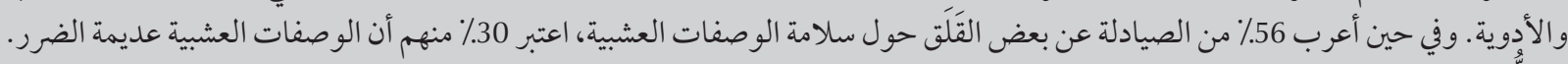

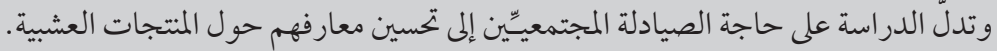

ABSTRACT There is an increasing trend towards consumption of complementary and alternative herbal products in many parts of the world. A cross-sectional sample of 115 community pharmacists in Riyadh, Saudi Arabia was visited and information on knowledge, attitudes and practices towards herbal remedies was collected using a structured questionnaire. All pharmacists acknowledged dispensing herbal products through their pharmacies. Ginseng was the most widely used product (47\%), followed by ginkgo (23\%), valerian (17\%) and St John's wort (3.5\%). In general, pharmacists had poor awareness about potential herb-drug interactions. While 56\% of participating pharmacists expressed concerns about the safety of herbal remedies, $30 \%$ considered them to be harmless. Community pharmacists need to be better informed about herbal products.

Connaissances, attitudes et pratiques des pharmaciens communautaires vis-à-vis des médicaments à base de plantes à Riyad (Arabie saoudite)

RÉSUMÉ Dans de nombreuses parties du monde, on observe une tendance croissante à la consommation de médicaments complémentaires et alternatifs à base de plantes. Des visites réalisées auprès d'un échantillon transversal de 115 pharmaciens communautaires de Riyad, en Arabie saoudite, et la distribution à ces derniers d'un questionnaire structuré ont permis de recueillir des informations sur leurs connaissances, leurs attitudes et leurs pratiques vis-à-vis des médicaments à base de plantes. Tous ont reconnu délivrer des produits à base de plantes dans leur officine. Le ginseng s'est avéré le plus utilisé (47\%), suivi par le ginkgo (23\%), la valériane (17\%) et le millepertuis (3,5\%). En général, les pharmaciens étaient peu conscients des éventuelles interactions entre plantes et médicaments. Alors que $56 \%$ des pharmaciens participants se sont montrés préoccupés par la sécurité des médicaments à base de plantes, 30 \% considèrent ceux-ci comme sans danger. Les pharmaciens communautaires doivent être mieux informés sur les produits à base de plantes. 


\section{Introduction}

In many parts of the world the consumption of herbal products is increasing, especially for the management of chronic diseases $[1,2]$. Studies in the United States reported a 380\% increase in the use of herbal remedies by patients between 1990 and 1997, and a 350\% increase in the use of herbal supplements between 1996 and 1999 [3,4]. Furthermore, it is now estimated that $30 \%-50 \%$ of the population of developed countries are using complementary and alternative medicine (CAM) products, and nearly US\$ 4 billion are spent on purchasing herbal products every year [5-7].

Despite this high rate of use, fewer than half of patients who use herbal products discuss the use of them with their clinicians $[8,9]$. Patients often do not consider these agents to be medicines because of their natural source or they may believe that their health care providers lack an understanding of, or have negative attitudes towards, herbal agents. In addition, health care providers may neglect to ask about use of herbal products [10]. In a review of 67 patients hospitalized for asthma treatment, none of the patients' records documented the use of CAM, although interviews indicated that over $40 \%$ of the patients had used herbal remedies as a treatment for asthma $[10,11]$.

The health care system in Saudi Arabia, as in most Middle East countries, is primarily based on conventional medicine. However, traditional local remedies continue to be very popular among Saudis $[12,13]$. In addition, there is an increasing trend towards the use of new, imported herbal products such as St John's wort, valerian and many others. This is a concern for local health care professionals. One clear difference between traditional herbs and these newer remedies is their availability in pharmaceutical dosage forms such as tablets, capsules and extracts. This has translated into provision of herbal products through community pharmacies rather than folk medicine shops where traditional herbal remedies are usually sold in their original crude forms.

Community pharmacists, as the most accessible health care providers [14], are receiving more queries from patients about herbal products than ever before [15]. Unfortunately, information about community pharmacist's knowledge of herbal products in Saudi Arabia is lacking. Therefore, the aim of the current study in Riyadh was to assess community pharmacists' knowledge, attitudes and dispensing practices concerning herbal products.

\section{Methods}

A cross-sectional survey of community pharmacists in Riyadh city was conducted over a period of 3 months between January and March 2008. Riyadh is the capital and biggest metropolitan city of Saudi Arabia with a population of about 5 million people.

\section{Sample}

A total of 115 community pharmacies in Riyadh city were randomly selected for visits based on their geographical distribution (i.e., north, south, east, and west). They represented about 15\%-20\% of all community pharmacies in the city. A typical community pharmacy in Saudi Arabia is usually operated by 1 licensed pharmacist and an assistant who work for about 8-12 hours per day, 6 days a week.

\section{Data collection}

A structured questionnaire was designed by the author and consisted of 3 main sections: demographic information, pharmacist's beliefs and dispensing practices regarding herbal products and a knowledge assessment section. A pilot testing was conducted to assure questionnaire's validity.
Questions on the types of herbal products available in the pharmacy, reasons why consumers acquire these products and the rate of dispensing them were included in the questionnaire. The demographic characteristics (sex and age group) of consumers of herbal medicines were estimated by pharmacists.

The pharmacist's knowledge section contained several measures. The first was a 5-point scale in which they rated their own knowledge about herbal products from 1 (excellent) to 5 (poor). Questions on their awareness to possible adverse effects of herbal products and herb-drug interactions was assessed by 3 options (yes/no/ don't know). The questionnaire also included questions about the source of information that pharmacists usually utilize to update their knowledge of herbal products. The knowledge component was further tested using a set of closed-book multiple choice questions relating to assumed indications, adverse reactions, precautions and important herb-drug interactions. For example: "St John's wort may decrease the blood level of which of the following drugs: a) aspirin; b) digoxin; c) ceftriaxone; d) ranitidine?"

Finally, professional attitudes towards these remedies were assessed with a 5-point scaling ranging from 1 (very effective) to 5 (not sure). In addition, the pharmacists' personal views about the safety of herbal products as therapeutic alternatives were included in the attitude assessment.

The selected pharmacies were visited and the questionnaire was filled during a 10-minute interview. Participation was anonymous.

\section{Analysis}

The data was entered into a Microsoft Access database and the frequencies of consumption of herbal products and consumers' characteristics and reasons for use of products were tabulated. The knowledge section was scored as the 
percentage of correct answers for each respondent. The chi-squared test was used for 2-way comparisons for nominal and categorical data which were analysed using SPSS, version 11.

\section{Results}

\section{Background characteristics}

A total of 115 interviews were conducted, a $100 \%$ response rate. The mean age of participants was 33 (standard deviation 7) years, with a median duration of 7 years in practice.

All pharmacists who were interviewed acknowledged that they dispensed herbal products to consumers. Almost two-thirds of pharmacists (63\%) reported receiving requests for herbal products daily, 32\% weekly and $5 \%$ monthly.

\section{Commonly dispensed herbal remedies}

Ginseng was the most widely dispensed, with $47 \%$ of pharmacists reporting that they dispensed this product, followed by ginkgo (23\%) and valerian (17\%) (Table 1 ). The main reasons for consumers to use herbal remedies according to pharmacists was for "boosting energy" or "enhancing physical performance" (reported by $49 \%$ of pharmacists). Other health-related problems for which herbal products were sought included poor mental alertness (19\%), insomnia $(17 \%)$, anxiety $(5 \%)$, and low mood (1\%).

The majority of those seeking herbal products were reported by pharmacists to be males, while females were only 24\%. Pharmacists reported that the majority of consumers were middle aged (around $47 \%$ of herbal product users), followed by the elderly (40\%) and young people (13\%).

Pharmacists' views on herbal products as alternative remedies showed that a considerable proportion (53\%) believed them to be effective or very effective (Figure 1). Despite this attitude, about half of the pharmacists (56\%) expressed concerns about the safety of herbal remedies, 30\% thought they were harmless and 14\% were not sure about their safety.

\section{Knowledge about herbal remedies}

When participating pharmacists were asked to self-rate their knowledge about herbs, $12 \%$ reported it as excellent, $34 \%$ as very good, $35 \%$ as good and $19 \%$ as fair. While the majority believed that their knowledge was good to excellent, the mean score of the multiple-choice questions used to assess acquaintance was $68 \%$ out of $100 \%$ (95\% confidence interval: 63\%-73\%), with possible adverse effects being the most well-known (Table 2). The majority of pharmacists (73\%) knew about possible herb-drug interactions, whereas $14 \%$ reported no known interactions and $13 \%$ were uncertain. Although many of the pharmacists acknowledged the existence of herb-drug interactions, they did not demonstrate a strong knowledge of the well-established interactions reported in the literature between selected herbs and common drugs.

A cross-tabulation using the chisquared test was used to assess differences in the frequency of pharmacists who had the most positive attitudes towards herbal products effectiveness (i.e. very effective and effective) versus those who were less persuaded about their effectiveness according to pharmacists' self-rated knowledge. Similarly, concern about herb-drug interactions and selfperceived knowledge was tested using the same approach. Those pharmacists who considered themselves to be wellinformed about herbal products had more positive attitudes towards the effectiveness of these alternative remedies as therapeutic options than those with less positive attitudes (33\% versus 13\%, $P<0.001)$. Nevertheless, pharmacists' self-rated knowledge did not affect their concerns about herb-drug interactions (38\% versus $46 \%, P=0.276$ ). Product package instructions were the most commonly used source of information by community pharmacists (40\%), followed by information obtained from product representatives (33\%), formal pharmacy education (21\%) and in a few cases via the Internet (6\%).

\section{Discussion}

It has been reported that $24 \%$ of patients attending a health centre in Saudi Arabia had used a local alternative remedy [16].

\begin{tabular}{lc}
\hline \multicolumn{2}{l}{ Table 1 Pharmacists' reports of herbal products commonly dispensed through } \\
\multicolumn{2}{l}{ community pharmacists and reasons why consumers use them } \\
\hline Item & \% of respondents ( $\boldsymbol{n}=\mathbf{1 1 5}$ ) \\
Herbal products commonly dispensed & 47 \\
Ginseng & 23 \\
Ginkgo & 17 \\
Valerian & 4 \\
St John's wort & 10 \\
Other (e.g. Echinacea, devil's claw, horse chestnut, & \\
passionflower, guarana) & 49 \\
Reasons why consumers use herbal products & 19 \\
Vitality & 17 \\
Mental alertness & 5 \\
Insomnia & 1 \\
Anxiety & 9 \\
Low mood & \\
Other (e.g. boosting immunity in children, arthritic & \\
pain, varicose veins, haemorrhoids, weight loss) & \\
\hline
\end{tabular}




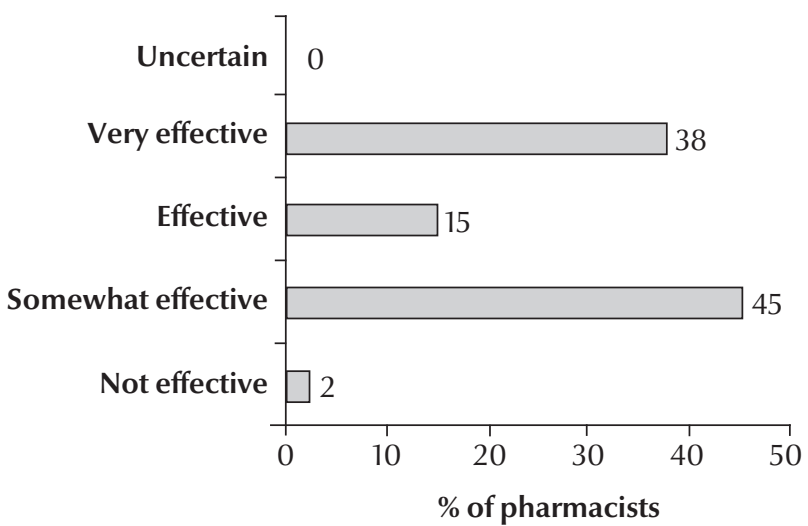

Figure 1 Pharmacists' attitudes toward herbal products as alternative therapeutic options $(n=115)$
Furthermore, the use of local herbal products reached $17 \%-33 \%$ among Saudi diabetics, and up to $73 \%$ of users did not inform their health care providers regarding their use of herbs [17]. As there is a wide belief in CAM in Saudi Arabia, and the community pharmacist is generally the first health care provider from whom patients seek recommendations on new products, more information about CAM is needed by community pharmacists. To the author's knowledge, this is the first study to examine community pharmacists' attitudes, knowledge and prescribing practices concerning herbal remedies in Saudi Arabia.

The currentstudyrevealed thatabout half of the community pharmacists in this sample in Riyadh (57\%) consider herbal products as potentially unsafe, whereas a considerable proportion (30\%) deemed them to be harmless. This was found despite the finding that $53 \%$ of pharmacists believed herbal remedies were effective or very effective. This generally positive attitude towards herbal remedies as safe and effective may influence patients, who may feel more comfortable using these products with their prescribed medications. Although it is likely that community pharmacists in Saudi Arabia have sufficient information about the indications for use of commonly dispensed herbs, they are less likely to be well-informed about potential herb-drug interactions. These results are similar to those found

\begin{tabular}{|c|c|c|}
\hline \multirow[t]{2}{*}{ Statement } & \multicolumn{2}{|c|}{$\%$ of respondents $(n=115)$} \\
\hline & Correct & Incorrect \\
\hline Echinacea is used to boost immunity & 91 & 9 \\
\hline Ginseng may increase blood pressure & 90 & 10 \\
\hline Ginseng should be avoided in diabetic patients & 90 & 10 \\
\hline $\begin{array}{l}\text { St John's wort is commonly used for mild to moderate } \\
\text { depression }\end{array}$ & 82 & 18 \\
\hline Ginkgo is claimed to delay dementia & 78 & 23 \\
\hline $\begin{array}{l}\text { Ginkgo can increase the risk of bleeding when } \\
\text { combined with warfarin }\end{array}$ & 60 & 40 \\
\hline St John's wort may increase blood digoxin level & 30 & 70 \\
\hline $\begin{array}{l}\text { Valerian should be used cautiously in patients using } \\
\text { benzodiazepines }\end{array}$ & 28 & 73 \\
\hline
\end{tabular}

among pharmacists in the United States [18-20].

The recent trend towards greater use of herbal products and the attitudes of pharmacists towards this trend have been evaluated by some investigators [20,21]. While some health care providers acknowledge that CAM may be of use, most know little about it [22]. Abahussain et al. have examined pharmacists' attitudes and awareness towards the use and safety of herbal products in Kuwait and found that about 31\% of the pharmacists did not have enough information about potential interactions between herbs and conventional medicines [23]. Similarly, the present study revealed that about $27 \%$ of community pharmacists in Saudi Arabia had little or no knowledge about important herb-drug interactions.

The study also found that ginseng was the most commonly dispensed alternative remedy by many community pharmacies in Riyadh, being dispensed daily in many instances. Ginseng is claimed to improve overall well-being and enhance stress resistance [24] and was mostly used to boost energy according to the interviewed pharmacists. Several adverse reactions have been reported with ginseng, including insomnia, hypoglycaemia, hypertension and skin reactions [25]. Furthermore, many prescription drugs have been reported to interact with ginseng, including oral hypoglycaemic agents, warfarin, nifedipine and loop diuretics [26]. Several herbal products found to be widely used in the current study have also demonstrated significant herbdrug interactions, including increased risk of bleeding with warfarin therapy in combination with ginkgo and increased digoxin levels with St. John's wort [26-28].

Finally, it is worth noting that the prevalence of chronic illnesses such as diabetes and cardiovascular diseases is rapidly increasing in Saudi Arabia due to a number of factors including lifestyle changes $[29,30]$. This has resulted 
in an expanding number of patients taking multiple medications, with a consequently greater potential for clinically significant interactions when herbal remedies are also consumed. Therefore, this potential problem in drug therapy needs further attention by pharmacists if they are recommending these products to patients. In particular, community pharmacists in Saudi Arabia need to be vigilant while establishing a dialogue with their patients regarding the use of herbal products with prescription medications. Patients should be informed about possible effects and closely monitored. In order to achieve these goals, continuing education programmes with more information on the safety and potential harmful effects of some CAM products should be provided to practising pharmacists.
Furthermore, all community pharmacies in Saudi Arabia should be equipped with evidence-based references on herb-drug interactions, such as a recent herbal textbook and/or an updated computer database on natural products.

Some important limitations should be considered when interpreting the results of the current work. First, in a cross-sectional study, data collection is limited to a single time point, so changes over time were not assessed. Secondly, there may have been errors by the pharmacists in recollecting the type and frequency of dispensed herbs as well as consumers' characteristics. In spite of these limitations, the present study lays a foundation for further work and guides the selection of appropriate measures to assess pharmacists' knowledge and patterns of practice of herbal products in Saudi Arabia in the future.

\section{Conclusions}

Despite the high provision of herbal remedies through community pharmacies in Saudi Arabia, the knowledge of pharmacists about herb-drug interactions was only moderate. Many community pharmacists in Riyadh believed that herbal products were an effective therapeutic option and a considerable proportion of pharmacists thought they were safe. Community pharmacists need to be better informed about herbal products and better able to advise and identify patients who are seeking alternative remedies for chronic health problems so as to refer them to other health care providers if necessary.

\section{Acknowledgements}

The author would like to thanks all pharmacists who participated in the study.

\section{References}

1. Astin JA. Why patients use alternative medicine: results of a national study. Journal of the American Medical Association, 1998, 279(19):1548-1553.

2. O'Hara M et al. A review of 12 commonly used medicinal herbs Archives of Family Medicine, 1998, 7(6):523-536.

3. Eisenberg DM et al. Trends in alternative medicine use in the United States, 1990-1997: results of a follow-up national survey. Journal of the American Medical Association, 1998, 280(18):1569-1575.

4. Gordon NP, Lin TY. Use of complementary and alternative medicine by the adult membership of a large northern California health maintenance organization, 1999. Journal of Ambulatory Care Management, 2004, 27(1):12-24.

5. Brevoort P. The booming US botanical market: a new overview. HerbalGram, 1998, 44:33-46.

6. Canedy D. Real medicine or medicine show? Growth of herba remedy sales raises issues about value. New York Times, 1998, July 23:C1.

7. Johnston B. One-third of nation's adults use herbal remedies: market estimated at 3.24 billion. Herbalgram, 1997, 40:49.

8. Eisenberg DM et al. Unconventional medicine in the United States. Prevalence, costs, and patterns of use. New England Journal of Medicine, 1993, 328(4):246-252.

9. Martin-Facklam M et al. Undeclared exposure to St. John's wort in hospitalized patients. British Journal of Clinical Pharmacology, 2004, 58(4):437-441.

10. Cockayne NL et al. Health professionals rarely record history of complementary and alternative medicines. British Journal of Clinical Pharmacology, 2005, 59(2):254-258.
11. Rivera JO et al. Herbals and asthma: usage patterns among a border population. Annals of Pharmacotherapy, 2004, 38(2):220-225.

12. Al-Awamy BH. Evaluation of commonly used tribal and traditional remedies in Saudi Arabia. Saudi Medical Journal, 2001, 22(12):1065-1068.

13. Al-Saeedi $\mathrm{M}$ et al. Patterns of belief and use of traditional remedies by diabetic patients in Mecca, Saudi Arabia. Eastern Mediterranean Health Journal, 2003, 9(1-2):99-107.

14. Your pharmacist serves you and your community. Alexandria, Virginia, Alliance for Pharmaceutical Care, 2003 [online brochure] (http://www.pharmacist.com/AM/ Template.cfm?Section=Search1\&section=Alliance_For_ Pharmaceutical_Care\&template=/CM/ContentDisplay. cfm\&ContentFileID=2696).

15. Clauson KA et al. Knowledge and attitudes of pharmacists in Missouri regarding natural products. American Journal of Pharmaceutical Education, 2003, 67(2):301-309.

16. Ajaji $\mathrm{N}$ et al. Prevalence of utilization of native medicine among primary care consumers. Saudi Medical Journal, 1998, 19:551-554.

17. Al-Rowais NA. Herbal medicine in the treatment of diabetes mellitus. Saudi Medical Journal, 2002, 23(11):1327-1331.

18. Bouldin AS et al. Pharmacy and herbal medicine in the US. Social Science \& Medicine, 1999, 49(2):279-289.

19. Rickert K et al. Pharmacist knowledge of common herbal preparations. Proceedings of the Western Pharmacology Society, 1999, 42:1-2. 
20. Chang ZG et al. Pharmacists' knowledge and attitudes toward herbal medicine. Annals of Pharmacotherapy, 2000, 34(6):710-715.

21. Koh HL et al. Pharmacists' patterns of use, knowledge, and attitudes toward complementary and alternative medicine. Journal of Alternative and Complementary Medicine, 2003, 9(1):51-63.

22. Nelson MV et al. Pharmacists' perceptions of alternative health approaches--a comparison between US and British pharmacists. Journal of Clinical Pharmacy and Therapeutics, 1990, 15(2):141-146.

23. Abahussain NA et al. Pharmacists' attitudes and awareness towards the use and safety of herbs in Kuwait. Pharmacy Practice, 2007, 5(3):125-129.

24. Kitts D, Hu C. Efficacy and safety of ginseng. Public Health Nutrition, 2000, 3(4A):473-85.
25. Coon JT, Ernst E. Panax ginseng: a systematic review of adverse effects and drug interactions. Drug Safety, 2002, 25(5):323344.

26. Izzo AA et al. Cardiovascular pharmacotherapy and herbal medicines: the risk of drug interaction. International Journal of Cardiology, 2005, 98(1):1-14.

27. Zhou S et al. Interactions of herbs with cytochrome P450. Drug Metabolism Reviews, 2003, 35(1):35-98.

28. Zhou S et al. Herbal modulation of P-glycoprotein. Drug Metabolism Reviews, 2004, 36(1):57-104.

29. Al-Nozha MM et al. Hypertension in Saudi Arabia. Saudi Medical Journal, 2007, 28(1):77-84.

30. Al-Nozha MM et al. Diabetes mellitus in Saudi Arabia. Saudi Medical Journal, 2004, 25(11):1603-1610.

\section{Practical aspects of signal detection in pharmacovigilance}

In recent years public expectations for rapid identification and prompt management of emerging drug safety issues have grown swiftly. Over a similar timeframe, the move from paper-based adverse event reporting systems to electronic capture and rapid transmission of data has resulted in the accrual of substantial datasets capable of complex analysis and querying by industry, regulators and other public health organizations.

Practical aspects of signal detection in pharmacovigilance aims primarily to provide a comprehensive resource for those considering how to strengthen their pharmacovigilance systems and practices, and to give practical advice. But the report does not specify instant solutions. These will inevitably be situation-specific and require careful consideration taking into account local needs. The report also looks ahead and anticipates a number of ongoing developments, including techniques with wider applicability to other data forms than individual case reports.

Further information about this and other WHO publication is available at: http://www.who.int/publications/en/ 